\title{
Access To WASH, Knowledge, Practice, and Protective Motivation Behaviour Towards COVID-19 Pandemic of Urban Marginalized Peoples
}

\section{Siwarat Pattanrsi}

Department of Public Works and Town\&Country Planning

Thi Phuoc Lai Nguyen ( $\sim$ phuoclai@ait.asia )

Asian Institute of Technology https://orcid.org/0000-0003-2827-5762

\section{Research}

Keywords: vulnerability, severity, self-efficacy, response efficacy, response barriers, slum communities, KAP, and PMT, Structural Equation Modelling.

Posted Date: October 18th, 2021

DOI: https://doi.org/10.21203/rs.3.rs-970712/v1

License: (c) (i) This work is licensed under a Creative Commons Attribution 4.0 International License. Read Full License 


\section{Abstract \\ Background}

Urban marginalized people are most vulnerable to the Covid-19 pandemic because of their poor water and hygiene conditions and high-density populated environment. However, there lack WASH facilities and theory-guided behavioural health intervention programs towards the Covid-19 pandemic in these fragile communities.

\section{Methods}

This study used the combined Knowledge- Practice -Theory (KAP) and Protection Motivation Theory (PMT) to predict the protective motivation behaviours of urban marginalized people against Covid-19. The phenomenological approach was applied to examine the slum communities' lived experiences during the COVID-19 pandemic. Data was collected through 105 semi-structured interviews and 453 questionnaires in two slum communities in Bangkok, Thailand.

\section{Results}

Results showed that most Thai slum people tended to have better access WASH and healthcare services and protection behaviours towards Covid-19 than other foreign migrant slum people. Structural Equation Modelling results illustrated that knowledge directly drove marginalized peoples' perceived vulnerability and practices, while practices influenced their perceived severity, self, and response efficacy which directly associated with their behavioural intentions.

\section{Conclusions}

Future pandemic prevention intervention programs should focus on vulnerability and severity through providing adequate WASH facilities and self-efficacy and response efficacy of protection motivation through enhancing community sensitization and awareness of COVID-19 protection.

\section{Introduction}

The coronavirus (COVID-19) pandemic is the most serious global health crisis we have faced since World War II. Since first being recorded in late 2019 in China, the Covid-19 coronavirus has spread to more than 200 countries around the world, caused 2.5 million deaths and 113 million infections (Johns Hopkins University, 2021). In this greatest challenge of the global health crisis, WASH (Water, Sanitation and Hygiene) and health facilities have become vital contributions to coronavirus disease prevention and response. However, one-third of people worldwide still lack access to WASH and health facilities, particularly marginalized and vulnerable people who live in the urban slum of many developing countries 
(WHO, 2020). Those people cannot fulfil the basic COVID-19 guidelines because of their poor housing quality, insecure residential status, and inadequate access to basic services and vital infrastructures such as water, sanitation, and hygiene.

Furthermore, because of unsafe water, inadequate sanitation, and poor hygiene, most people in the vulnerable communities often suffer from water-borne diseases such as diarrhoea, acute respiratory infection, and skin infections (Pati, 2014). Admittedly, slum communities are most vulnerable and exposed to the infection during the crisis due to poverty shocks, limited access to healthcare facilities and basic WASH services, and adequate housing (Konteh, 2009; WHO, 2020; U.N., 2020). Marginalized people also have low awareness and knowledge related to disease and WASH practice which can cause poor health conditions and unsafe protective practices (Hsan et al., 2019).

Many international development organizations (e.g., WHO, 2020; UNICEF, 2020; UNESCO,2020) have promoted WASH projects as measures against COVID-19 in fragile countries. However, sustainable strategies and tactics for implementing the WASH response require understanding public knowledge, perception, and practices in preventing and protecting from Covid-19. Understanding public WASH and health protection knowledge, perception, and practice can help to identify factors influencing people's health behaviours in adopting responsive practices towards the COVID-19 pandemic (Podder et al., 2019). Knowledge enhancing and education interventions are probably self-protective measures in tackling pandemics for marginalized people (Al-Hanawi1 et al., 2020). Protecting marginalized groups contributes to protecting their risks, and the whole society as a COVID-19 infectious agent could quickly spread out within and among the community.

Through a case study of urban slum communities in Bangkok, Thailand, this study aimed to examine (i) the causal relationship between WASH facilities and marginalized people's vulnerability and severity toward Covid -19 pandemic, (ii) how their protective behaviours are shaped by their vulnerability, severity, knowledge, and attitude. We combine Knowledge - Attitude - Practice Theory (KAP) and Protection Motivation Theory (PMT), to predict people's intentional behaviours towards protecting infectious pandemics.

\section{Conceptual Model}

\subsection{Knowledge, Attitude, and Practice Theory (KAP)}

Knowledge, attitude, and practice (KAP) theory is commonly applied in public health research and practice. It is widely used in health studies emphasizing knowledge, attitudes, and practices in reducing the risk of communicable diseases caused by poor hygiene practices and inadequate sanitary conditions (Demberere, 2015, Montoute and Cashman, 2015, Mubarak et al., 2016). Many studies showed the poor status regarding knowledge, attitudes, and practices (KAP) of hygiene in many developing countries such as Ethiopia (Goodwin et al., 2015), Bangladesh (Islam et al., 2020). If an individual knows, learns, and follows WASH and health protection guidelines, it helps them mitigate the risk of communicable diseases 
(Barnard et al., 2013; Berhe et al., 2020). Some scholars have demonstrated the link between knowledge and practice and between attitudes and practices (e.g., Pratkanis et al., 1989, Westaway et al, 2000; Nguyen et al., 2019). Thus, previous studies in the field revealed that people with good WASH and health protection knowledge and correct attitudes would follow safety practices towards hygiene and selfprotection (Özdemir et al., 2011).

\subsection{Protection Motivation Theory (PMT)}

Protection Motivation Theory (PMT) is developed by Roger (1975) which is widely used to predict health intention and practice in diverse studies' contexts such as water management, disaster, waste management, infection diseases (Nelson et al., 2012; Xiao et al., 2016; Janmaimool, 2017; Tang and Feng, 2016). PMT proposes the framework to understand how individuals are motivated to react to threats, explain why people engage in unhealthy practices and suggest how to change behaviours through education and awareness-raising (Bockarjova and Steg, 2014; Westcott et al., 2017). The PMT has two major distinct cognitive processes, including threat appraisal and coping appraisal. The threat appraisal component is used to evaluate people's perception of the severity and vulnerability of certain behaviours. In contrast, the coping appraisal is used to evaluate people's ability to cope and respond to threats and remove barriers from specific actions consisting of response-efficacy and self-efficacy. Many previous studies related to the health sector showed that response-efficacy and self-efficacy are associated with health-protective behaviours intention (e.g., Westcott et al., 2017; Mortada et al., 2020; Hernandez-Padilla et al., 2020). Some studies (e.g., Xiao et al.,2014; Bashirian et al., 2020) revealed that both threat appraisal and coping appraisal have a higher ability to predict protective intentions. In addition, there is an external factor such as knowledge which is linked to threat perception and intention, thus influencing behaviours changes (Pham et al., 2012; Chamroonsawasdi et al., 2017). Tang and Feng (2018) found that intention was a mediator variable between PMT elements and actual behaviours. The perception of risk and benefit of actions encourage higher intention and transform into actual practice (Fishbein et al., 2001).

Knowledge and Current Practice are associated with cognitive processes such as information, knowledge, actual behaviours. These components can influence people's perceived risk, vulnerability, and severity (Eppright et al., 1994) and help to predict protective behaviours in the future resulted from threat appraisal and coping appraisal (Xiao et al., 2014; Tang, 2018; Fishbein et al., 2001; Tang and Feng, 2018) Therefore, a combined theoretical framework included Knowledge-Practice and PMT in this study aimed to explore factors motivated or restrained protective motivation behaviours of marginalized urban people during the crisis and shaped protective practices towards COVID-19 protection.

\section{Methodology}

\subsection{Selection of the study area}

Khlong Toei slum communities, Bangkok, Thailand, are selected purposely for this study (Fig. 1). Khlong Toei slum communities are the largest slum in Thailand, with 49,225 households and more than 100,000 
populations in which the majority are vulnerable and at risk. They are seasonal workers in Khlong Toei port and the largest fresh and retail markets in Bangkok, severely impacted during the COVID-19 crisis. Their WASH condition is likely poor because there are no inadequate facilities and public goods

Lock 1-2-3 and Ban Guay sub-community were selected as case study areas by considering the characters between two sub-communities: environment, living condition, location, and sensitive issues inside the community. Lock 1-2-3 sub-community located near Art Narong Road with a high density of household cluster while Ban Guay sub-community located along the canal and under troll way road. Lowquality drinking water with a high level of bacteria inside water tanks in vending machines was captured in the selected areas (Goodwin et al, 2015).

\subsection{Research design}

The research was designed following a phenomenological approach that highlights slum communities' lived experiences of the COVID-19 pandemic (Creswell, 2018). Data collection was conducted with integrated methods, including semi-structured interviews and questionnaire surveys.

\subsubsection{Semi-structured interviews:}

Semi-structured interviews were carried out with 105 representative people from communities and nine staff from 7 organizations who work with marginalized groups. Each interview lasted 30 mins. Most questions are open-ended to explore their experiences with the COVID-19 pandemic and challenges regarding inadequate WASH facilities, knowledge, attitude, and protective behaviours towards COVID -19 protection.

\subsubsection{Questionnaire survey}

The questionnaire survey was conducted with 385 people in the Lock 1-2-3 sub-communities and 68 people in Ban Guay sub-communities, making 453 respondents. The main criteria of selecting respondents from these two communities are "access WASH and health facility" and "non-access WASH and health facility". Respondents were randomly selected from two selected sub-communities by using Slovin's Formula and snowball sampling method. Methods are suitable for hidden populations, particularly in slum communities with little information or unknown and anonymous population census data (Baltar and Brunet, 2012). Thus, 349 respondents with access WASH and health facilities and 104 non-access WASH and health facilities were selected for the survey sample. To cover different socioeconomic, ethnic, and cultural characteristics of the whole slum community population, some other criteria have been made for the sampling, including ethnicity, age range, gender, health condition, and disabilities. The population list of Khlong Toei slum communities was obtained from the National Statistical Office of Thailand (2019) and Duang Prateep Foundation's suggestion.

The questionnaire sheet is attached in Appendix A 
The questionnaire survey was administered in the Thai language by eleven trained field assistants with three staff members from the Duang Prateep Foundation. They have intensive experience in working with these slum communities. All field assistants were trained to seriously consider the ethical consideration, privacy, and integrity in the social survey.

\subsection{Data analysis}

This study used mixed qualitative and quantitative data analysis methods. Data from the interview and questionnaire survey were treated as anonymous. In the qualitative data analysis method, the phenomenology research approach was deployed to discover and describe urban marginalized people's experiences and behaviours towards the COVID-19 phenomenon and find the key factors contributing to their perceptions, attitudes, and responses. The authors generated themes for analysing significant statements based on PMT components and developed clusters of meaning from interviewing. This task aimed to describe significant statements and communicate the understanding of the essence of a phenomenon in terms of conditions, situation, or context (Creswell, 2018).

In quantitative data analysis, statistics tools were applied for the analysis of questionnaire survey data. Descriptive statistics were used to describe the level of respondents' knowledge, practices, attitudes, and behaviours. Fisher's exact test was applied to test the difference in socio-demographic and cultural characteristics from the two respondent groups of access to health facility and non-access health facility. T-test was used to compare respondents' knowledge, practices, attitudes, and behaviours among sociodemographic, ethnic, and cultural groups. All statistical analyses were conducted in IBM SPSS Statistics 26 with a significant level of less than $5 \%$.

Partial least square structural equation modelling (PLS-SEM) was performed via two vital stages: the measurement/outer and structural/inner models (Hair et al., 2017). Accordingly, seven constructs were modelled by formative measurements to evaluate the causal relationships between the latent constructs calculated by 22 items through the path model analysis. Since all constructs are modelled based on a formative measurement model, two criteria are used to assess the inner model, including collinearity issues and the significance and relevance of the formative indicators (Hair et al., 2017). Regarding the assessment of the level of collinearity, the variance inflation factor (VIF) was computed. SII indicator's tolerance (VIF) was below the threshold value of 5 . The values of the outer weights and the corresponding items' loading were estimated to interpret the formative indicators' absolute and relative contributions. The values of external loadings of variables used in the model were higher than 0.5

\section{Results}

\subsection{Socio-Demographic characteristics of the Respondents}

Table 1 showed demographic profiles of two slum community groups: access WASH/health facility and non-access WASH/health facility. There was no difference in numbers between the two groups in terms of age, gender, ethnicity, and house occupancy. 
Page $7 / 24$ 
Table 1

Comparisons among two respondent groups of access and non-access WASH and health facility.

\begin{tabular}{|c|c|c|c|c|}
\hline Variable & $\begin{array}{l}\text { Frequency } \\
(\%)\end{array}$ & $\begin{array}{l}\text { Access WASH \& } \\
\text { health facility }\end{array}$ & $\begin{array}{l}\text { Non-access WASH \& } \\
\text { health facility }\end{array}$ & $p$-value ${ }^{1}$ \\
\hline $\begin{array}{l}\text { Total number of } \\
\text { respondents }\end{array}$ & 453 & 349 & 104 & \\
\hline \multicolumn{5}{|l|}{ Age (Years) } \\
\hline $15-17$ & $42(9.3 \%)$ & $37(10.6 \%)$ & $5(4.8 \%)$ & \multirow[t]{4}{*}{0.066} \\
\hline $18-35$ & $\begin{array}{l}168 \\
(37.1 \%)\end{array}$ & $136(39 \%)$ & $32(30.8 \%)$ & \\
\hline $36-59$ & $136(30 \%)$ & $98(28.1 \%)$ & $38(36.5 \%)$ & \\
\hline $60-90$ & $\begin{array}{l}107 \\
(23.6 \%)\end{array}$ & $78(22.3 \%)$ & $29(27.9 \%)$ & \\
\hline \multicolumn{5}{|l|}{ Gender } \\
\hline Male & $\begin{array}{l}220 \\
(48.6 \%)\end{array}$ & $168(48.1 \%)$ & $52(50 \%)$ & \multirow[t]{3}{*}{0.866} \\
\hline Female & $\begin{array}{l}232 \\
(51.2 \%)\end{array}$ & $180(51.6 \%)$ & $52(50 \%)$ & \\
\hline Transgender & $1(0.2 \%)$ & $1(0.3 \%)$ & - & \\
\hline \multicolumn{5}{|l|}{ Ethnicity } \\
\hline Thai & $\begin{array}{l}401 \\
(88.5 \%)\end{array}$ & $311(89.1 \%)$ & $90(86.5 \%)$ & \multirow[t]{5}{*}{0.208} \\
\hline Myanmar & $28(6.2 \%)$ & $20(5.7 \%)$ & $8(7.7 \%)$ & \\
\hline Laos & $8(1.8 \%)$ & $8(2.3 \%)$ & - & \\
\hline Cambodia & $12(2.6 \%)$ & $8(2.3 \%)$ & $4(3.9 \%)$ & \\
\hline Rohingya & $4(0.9 \%)$ & $2(0.6 \%)$ & $2(1.9 \%)$ & \\
\hline \multicolumn{5}{|c|}{ Legal marital status } \\
\hline Single & $\begin{array}{l}205 \\
(45.2 \%)\end{array}$ & $158(45.3 \%)$ & $47(45.2 \%)$ & \multirow[t]{5}{*}{$0.004^{*}$} \\
\hline Married & $\begin{array}{l}195 \\
(43.1 \%)\end{array}$ & $146(41.8 \%)$ & $49(47.1 \%)$ & \\
\hline Separated & $13(2.9 \%)$ & $11(3.2 \%)$ & $2(1.9 \%)$ & \\
\hline Cohabitation & $15(3.3 \%)$ & $15(4.3 \%)$ & - & \\
\hline Widow(er) & $25(5.5 \%)$ & $19(5.4 \%)$ & $6(5.8 \%)$ & \\
\hline
\end{tabular}




\begin{tabular}{|c|c|c|c|c|}
\hline Variable & $\begin{array}{l}\text { Frequency } \\
\text { (\%) }\end{array}$ & $\begin{array}{l}\text { Access WASH \& } \\
\text { health facility }\end{array}$ & $\begin{array}{l}\text { Non-access WASH \& } \\
\text { health facility }\end{array}$ & p-value ${ }^{1}$ \\
\hline \multicolumn{5}{|c|}{ State of residential occupancy } \\
\hline Owner occupied & $\begin{array}{l}54 \\
(11.9 \%)\end{array}$ & $51(14.6 \%)$ & $3(2.9 \%)$ & \multirow[t]{5}{*}{$<0.001^{*}$} \\
\hline Squatter & $\begin{array}{l}216 \\
(47.7 \%)\end{array}$ & $171(49 \%)$ & $45(43.3 \%)$ & \\
\hline Tenant & $\begin{array}{l}106 \\
(23.4 \%)\end{array}$ & 79 (22.6\%) & $27(26 \%)$ & \\
\hline $\begin{array}{l}\text { Living with a host } \\
\text { family }\end{array}$ & $21(4.6 \%)$ & $14(4 \%)$ & $7(6.7 \%)$ & \\
\hline Others & $\begin{array}{l}56 \\
(12.4 \%)\end{array}$ & $34(9.8 \%)$ & $22(21.1 \%)$ & \\
\hline \multicolumn{5}{|l|}{ Educational level } \\
\hline None & $\begin{array}{l}79 \\
(17.4 \%)\end{array}$ & $44(12.6 \%)$ & $35(33.7 \%)$ & \multirow[t]{5}{*}{$<0.001^{*}$} \\
\hline Primary & $\begin{array}{l}92 \\
(20.3 \%)\end{array}$ & $81(23.2 \%)$ & $11(10.6 \%)$ & \\
\hline Secondary & $\begin{array}{l}112 \\
(24.7 \%)\end{array}$ & $84(24.1 \%)$ & $28(26.9 \%)$ & \\
\hline Tertiary & $145(32 \%)$ & $121(34.7 \%)$ & $24(23.1 \%)$ & \\
\hline Others & $25(5.6 \%)$ & $19(5.4 \%)$ & $6(5.7 \%)$ & \\
\hline \multicolumn{5}{|l|}{ Occupation } \\
\hline Trader & $\begin{array}{l}65 \\
(14.3 \%)\end{array}$ & $52(14.9 \%)$ & $13(12.5 \%)$ & \multirow[t]{7}{*}{$0.022^{*}$} \\
\hline Daily wage-earner & $\begin{array}{l}153 \\
(33.8 \%)\end{array}$ & $124(35.5 \%)$ & $29(27.9 \%)$ & \\
\hline Public Servant & $1(0.2 \%)$ & $1(0.1 \%)$ & - & \\
\hline Unemployed & $\begin{array}{l}101 \\
(22.3 \%)\end{array}$ & $67(19.2 \%)$ & $34(32.7 \%)$ & \\
\hline Student & $\begin{array}{l}81 \\
(17.9 \%)\end{array}$ & $64(18.3 \%)$ & $17(16.3 \%)$ & \\
\hline Private employee & $23(5.1 \%)$ & $21(6.1 \%)$ & $2(1.9 \%)$ & \\
\hline Others & $29(6.4 \%)$ & $20(5.9 \%)$ & $9(8.7 \%)$ & \\
\hline
\end{tabular}


The majority of respondents from WASH access group were adult group between 18-35 years than the non-access group. Around $27.9 \%$ of respondents with non-WASH access had over 60 years old. The majority of Thai people can access WASH and healthcare services, while few of ethnic migrants had access these services during the COVID-19 crisis. $49 \%$ of respondents who are squatter occupied can access those healthcare services but around $43 \%$ of them are non-access WASH \& health facility ( $p$ $<0.001)$. Respondents with WASH access tended to have a higher education level $(p<0.001)$ and are single $(p=0.004)$. Most of daily wage-earner can access WASH and healthcare services while around 32.7 $\%$ of unemployed cannot access the healthcare services $(p<0.001)$.

\subsection{WASH conditions of slum communities during COVID- 19 pandemic}

Figure 2 depicts respondents' statements about their living conditions and their access to WASH facilities.

\section{Access to clean water}

The majority of respondents have access to tap water, while around 100 households cannot access clean water. Residents who can afford clean drinking water have in-home water filters for domestic washing. Those who cannot afford a tap water system in their house have to use water from the canal for domestic washing and buy water from the vending machine for drinking. Some people having no access to tap water pay a monthly water meter rental from their neighbourhood. Moreover, during the crisis, residents in the Khlong Toei slum communities cannot pay water bills due to the loss of jobs, making their living conditions poorer. They live with clean drinking water and food from donations. The majority of people having no access to clean water are mostly foreign workers, homeless, and families living in non-standard houses such as under the toll-way and the railroad. However, the evidence showed that the water quality of water vending machines located in the community is undrinkable due to the high level of pathogens (Goodwin et al., 2015). Furthermore, the water quality of the Khlong Toei canal, where these people collect and storage for domestic use, has a Biochemical Oxygen Demand (BOD) value higher than the average acceptable value. The canal water is polluted because of solid and organic waste released directly to the water from markets and domestic houses.

\section{Sanitation}

Most households had their private toilet but with a very small size and lack of sanitation standards. Some residents lived under the toll-way bridge, which did not have a private toilet. In individual houses, there was no waste separation. However, community staff keeps garbage bags in front of the residents' homes and separate garbage in the community centre. Many types of garbage, including plastic bags, water bottles, food scraps, are directly thrown into the roads and canals.

\section{Hygiene}


Since COVID-19 rises, marginalized people's hygiene practice has changed. They wore medical masks to protect against infection in public places and frequently washed their hands with clean water and sanitiser gel. Community leaders provided masks and hygiene products at the handwashing station in the community centre. However, their living condition was not suitable for social distancing. Most respondents also expressed that they cannot afford alcohol gel and medical masks for everyday use. In the post-lockdown period, most slum people did not wear masks and less washing hands because of the reasons mentioned above.

\subsection{Slum communities' KAP and protective motivations towards COVID-19}

Figure 3 depicts statements of different socio-demographic groups of interviewed marginalized people about their perceptions of threats and risks and coping benefits and barriers, and protective intentions. They considered themselves and their family members vulnerable because of their exiting health and hygiene conditions such as chronic disease, poor housing, population density, and lack of WASH facilities. They perceived the severity of the situation as their seasonal jobs do not allow them to practice COVID-19 protection practices. They feared hunger and poverty rather than COVID-19 infection. At the same time, they were anxious and worried about death and sickness caused by the coronavirus. However, they perceived self-efficacy in coping with the pandemic. They were confident in disease and protection awareness and practice, their trust in community cooperation, and the government's information in combating the pandemic. Interviewees believed their practices towards COVID-19 prevention, including wearing masks, social distancing, and washing hands would help them to reduce risks. However, they also perceived coping barriers because of the high cost of medical masks that they cannot afford, their nature of work in crowded markets and ports where they do not allow them to practice social distancing, and their social status non-access to WASH, public healthcare, and online information.

Table 2 reports respondents' KAP and perceived threats/risks and coping benefits and barriers towards COVID-19. In general, the survey showed respondents have good knowledge, practice, and strong perceptions of vulnerability, severity, self-efficacy, response efficacy, and protective behavioural intention towards COVID-19. There are no differences in knowledge, practice, vulnerability, perceived self-efficacy, response efficacy, and response cost among the two groups. However, respondents with access WASH and health facilities perceived the COVID-19 more severe $(t=-3.807, p<0.001 ; \mathrm{df}=451)$ and had higher protective intention $(t=-3.947, p<0.001 ; d f=431)$ than their counterparts. 
Table 2

Surveyed comparison of respondents' KAP and protective motivation towards COVID 19 protection.

\begin{tabular}{|lllllllll|}
\hline Constructs & Mean & Median & Std. & $\begin{array}{l}\text { Access } \\
\text { WASH } \\
\text { \&health } \\
\text { facility }\end{array}$ & $\begin{array}{l}\text { Non-access } \\
\text { WASH\& } \\
\text { health } \\
\text { facility }\end{array}$ & ttest & $d f$ & $\begin{array}{c}p \text { - } \\
\text { value }\end{array}$ \\
\hline Knowledge & 3.894 & 3.85 & 0.622 & 3.851 & 3.939 & -1.496 & 451 & 0.135 \\
\hline Practice & 3.809 & 3.80 & 0.691 & 3.871 & 3.749 & -1.885 & 451 & 0.060 \\
\hline $\begin{array}{l}\text { Perceived } \\
\text { Vulnerability }\end{array}$ & 3.378 & 3.40 & 0.838 & 3.378 & 3.377 & -0.006 & 449 & 0.995 \\
$\begin{array}{l}\text { Perceived } \\
\text { Severity }\end{array}$ & 3.872 & 4.00 & 0.746 & 4.007 & 3.744 & -3.807 & 451 & $<0.001$ \\
\hline $\begin{array}{l}\text { Perceived } \\
\text { self-efficacy }\end{array}$ & 3.723 & 3.75 & 0.855 & 3.767 & 3.681 & -1.067 & 451 & 0.286 \\
\hline $\begin{array}{l}\text { Response } \\
\text { efficacy }\end{array}$ & 4.173 & 4.00 & 0.631 & 4.228 & 4.120 & -1.838 & 451 & 0.067 \\
\hline $\begin{array}{l}\text { Protective } \\
\text { intention }\end{array}$ & 4.204 & 5.00 & 0.658 & 4.326 & 4.088 & -3.947 & 431 & $<0.001$ \\
\hline
\end{tabular}

\subsection{Prediction of intentional protective behaviours from the structural equation modelling (SEM) analysis}

Figure 4 shows the relationship among knowledge, perceived threats/risks, and coping barriers, protective motivation behaviours and practice. The root means square residual SRMS was $<0.08$, NFI was $>0.09$, and Chi-square was $>200$ meant that the data fit the hypothesized model well; NFI $=0.905$, SRMS $=0.047$, Chi-square/df $=403.699, p<0.01$ and $p<0.05$. Thus, the model can predict protective motivation behaviours.

The model results show that knowledge strongly influences current practice $(\beta=0.456, p<0.001)$ and perceived vulnerability $(\beta=0.180, p<0.001)$, while perceived vulnerability influences current practices $(\beta=$ $0.163, p=0.002)$. At the same time, current practice influences perception of self-efficacy $(\beta=0.314$, $p<0.001)$, response efficacy $(\beta=0.557, p<0.001)$, and severity $(\beta=0.198, p=0.003)$. The model results also confirmed that perceived severity influences protective behaviour intention $(\beta=0.102, p=0.043)$. If people tend to have high awareness about health and disease consequences, they will have the motivation to adopt protective behaviours. And people with high individual's self-efficacy tend to perceive themselves to be able to cope with the disease, leading to high preventive motivation as perceived self-efficacy influences protective motivation behaviours $(\beta=0.293, p<0.001)$.

Perceived response efficacy is also confirmed to influence protective motivation behaviours $(\beta=0.417$, $p<0.001)$. Response efficacy was a variable supporting self-efficacy by enhancing a high level of self- 
protection. Both self-efficacy and response efficacy were found as effective variables to predict people's protective behaviours.

\section{Discussion}

\subsection{Role of WASH and health facility and knowledge in urban marginalized people's threat and coping appraisal}

Although WASH has a vital role in combating COVID-19 in the developing world (Ezbakhe et al., 2019, UN,2020; UNICEF, 2020), the findings of this study showed that urban marginalized people have inequalities access to clean water, poor sanitation, shortages of personal protective equipment and public healthcare services. The situation of urban marginalized people in Thailand is similar to many developing countries such as Kenya, Africa, Pakistan, India, where poor people and low-skilled worker migrants struggle to access healthcare services and unaffordable protective equipment (Zulu et al., 2011; UNESCO, 2020).

The findings revealed that the marginalized urban people tended to have basic knowledge of COVID-19, WASH practices, and a high perception of threat and coping appraisal and protective intention. People who can access WASH and health care tended to have higher protection intention against COVID-19, and as a result, perceive the pandemic more severe than people having no access to WASH and healthcare. Most Thai respondents tended to have better access these public services and have higher education (nearly $50 \%$ of respondents had tertiary education) than non-Thai migrant groups. The barriers to WASH and healthcare services are due to unemployment, hidden social status, expensive health insurance, low health literacy, language barrier, and social stigma decrease the protective motivation awareness of marginalized people (Essendi et al., 2011; George et al.,2018) which may constraint their protection intentions toward Covid-19.

\subsection{Predicting protective motivation behaviours towards health infection.}

This study developed a conceptual framework based on Protective Motivation Theory (PMT) and Knowledge, Attitude, and Practice (KAP) to predict WASH protective behaviours intention against COVID19. PMT is a social cognitive process with information, knowledge, and attitude (Milne et al., 2000), and many researchers widely used PMT in predicting 'intention' behaviours. Therefore, it can be an alternative theory for KAP to investigate people's knowledge and experiences relevant health behaviours (Xiao et al., 2014), and PMT components should be considered in KAP because it provides a strong predictor and fills the gap of the prediction results (Nabizadeh et al., 2014).

In this study, a part of PMT plays a role in the 'attitude' component in the KAP model, including perceived severity, self-efficacy, and response efficacy. The combination of PMT and KAP helps researchers to understand knowledge significantly affects current practices and vulnerability due to knowledge linked to 
people's awareness, motivation, and competence to understand, appraise, assess health risk or vulnerability situations leading people to judge and form accurate decisions by maintaining or improving their health practices regarding disease prevention and health protection (He et al., 2016). The model results showed that knowledge was a vital factor that had a greater influence on practice (Allan et al. 2013) and behaviour intention through threat appraisal and coping appraisal (Rogers,1983; Renner et al. 2008). It also can shape people's risk perception, which helps to decrease people's perceived severity and vulnerability beliefs (Eppright et al., 1994). Vulnerability can help to predict intentional behaviours as it is significantly associated with people's knowledge and emotions. These emotions such as fear, anxiety are roots of people's survival favouring the prediction of health preventive behaviours (Stangier et al., 2021).

The results also showed that current practices could influence the perception of coping appraisal and threat appraisal. If people have good current practices, it can reduce or prevent the severity of harmful events and increase the perception of self-efficacy and response efficacy regarding disease prevention benefits. Poor health practices or negative bias on health practices can undermine protective behavioural intention (Nguyen et al., 2019a; Park et al., 2020). Current practices can influence people's health behavioural intention (Fishbein et al., 2001; Chamroonsawasdi et al., 2017).

The model also confirmed that perceived severity, self-efficacy, response efficacy are all three variables influencing protective motivation behaviours. People with high awareness of health and disease severity will have high motivation to adopt protective behaviours (Tazval et al.,2016; Ezati et al., 2021). Whereas perceived self-efficacy is the strongest factor among PMT constructs, many studies found (e.g., Hernandez-Padilla et al., 2020; Janmaimool, 2020). People with high efficacy tend to cope with the disease, leading them to have higher preventive motivation (Leigh et al., 2020). Furthermore, perceived response efficacy is found as a variable supporting self-efficacy (Rippetoe et al.,1987; Milne et al., 2000; Leigh et al., 2020). Response efficacy can enhance self-efficacy on self-protection. Protective motivation behaviours have resulted from threat appraisal and coping appraisal (Fishbein et al., 2001; Tang and Feng, 2018). Thus, the model results revealed that the field data in this case study fits well the conceptual model by combining KAP and PMT to predict urban marginalized people's protective motivation behaviours towards Covid-19.

\section{Conclusions And Implications}

Despite the great effort of international development organizations and governments in the urban WASH program, many marginalized communities still live in poor urban environments across the world. This study depicted a rich picture of the real-life of the marginalized people who live in slums. Many impoverished urban settlements are being deprived of their right to water and sanitation, with severe implications on their prevention and survival from both epidemic and pandemic.

The study also showed that knowledge plays a key role in marginalized people's perceived vulnerability and current practices, while current practice strongly influences severity, self-efficacy, and response efficacy. Furthermore, protective motivation behaviours are associated with severity, self-efficacy, and 
response efficacy. Although the findings showed that the marginalized in this study had a high level of protective behaviours intention and protective practices, they were unable to practice the basic Covid -19 prevention exercises due to no access to clean water, poor sanitation infrastructure, unaffordable protective equipment. Protecting a community from a communicable disease means protecting the whole society from the pandemic. This study appeals to the urgent intervention and special assistance from development organizations, the government, and the society in enhancing the needs of marginalized communities by ensuring their access to clean water, sanitation, and health care services. Any WASH and health programs in responding to epidemics or pandemics in the future must integrate the socio-cognitive behaviours intervention aiming at improving their knowledge, practice, and perception of threat appraisal and coping strategies to the infectious disease.

Finally, the study applied a social cognitive conceptual model by combining KAP and PMT in predicting health behaviours, aiming at devising intervention programs and policies for purposeful behaviours change. Although KAP and PMT have been widely used in psychological research to predict health behaviours, this is the first study to investigate the applicability of the combined KAP and PMT in understanding the Covid-19 protective behaviours among marginalized communities in Thailand. The field data fit the hypothesized model well, and the model also has adequate validity because the motivation intention was associated with PMT constructs used in the study.

\section{List Of Abbreviations}

KAP: Knowledge, Attitude and Practices

PMT: Protective Motivation Theory

SEM: Structural Equation Modelling

WASH: Water, Sanitation and Hygiene

\section{Declarations}

\section{Ethics approval and consent to participate}

The interview and questionnaire survey protocol were approved by the research ethics review committee (RERC) at the Asian Institute of Technology (AIT), Thailand. The written consent was obtained from all participants who took part in the study. During the interview and questionnaire survey, interviewers and interviewees always wore medical masks and maintained social distance for preventing COVID-19 transmission and following regulations that applied during the COVID-19 situation in Thailand.

\section{Consent for publication}

The manuscript contains no individual person's data in any form (including any individual details, images or videos), all data obtained interview and questionnaire survey were treated as anonymous. Interviews 
and questionnaires with teenagers from 15-17 were made under the observation of their parents.

\section{Availability of data and materials}

The datasets used and/or analysed during the current study are available from the corresponding author on reasonable request.

\section{Competing interests}

The authors declare that they have no competing interests

\section{Funding}

The authors acknowledged H.M. Queen scholarship of Thai Royal Government

\section{Authors' contributions}

SP: Methodology; Investigation, Formal analysis, Visualization, Writing - original draft; TPLN:

Conceptualization, Methodology, Validation; Writing - original draft; Review \& editing; Supervision.

\section{Acknowledgements}

The authors would like to thank Duang Prateep Foundation and Khlong Toei slum communities in Thailand who were involved in this research directly and indirectly.

\section{References}

1. Al-Hanawi MK, Angawi K, Alshareef N, Qattan AMN, Helmy HZ, Abudawood Y, et al. Knowledge, Attitude and Practice Toward COVID-19 Among the Public in the Kingdom of Saudi Arabia: A CrossSectional Study. Front Public Heal [Internet]. 2020;8:217. Available from: https://www.frontiersin.org/article/10.3389/fpubh.2020.00217.

2. Allan C, Nguyen T, Seddaiu G, Wilson B, Roggero PP. Integrating local knowledge with experimental research: Case studies on managing cropping systems in Italy and Australia. Ital J Agron. 2013 May 17;8:108. Bagozzi, R. (1981). Attitudes, Intentions, and Behavior: A Test of Some Key Hypotheses. Journal of Personality and Social Psychology, 41, pp.607-627.

3. Baltar F, Brunet I. Social research 2.0: virtual snowball sampling method using Facebook. Internet Res [Internet]. 2012 Jan 1;22(1):57-74. Available from: https://doi.org/10.1108/10662241211199960.

4. Barnard S, Routray P, Majorin F, Peletz R, Boisson S, Sinha A, et al. Impact of Indian Total Sanitation Campaign on Latrine Coverage and Use: A Cross-Sectional Study in Orissa Three Years following Programme Implementation. PLoS One. 2013 Aug 21;8:e71438.

5. Bashirian S, Jenabi E, Khazaei S, Barati M, Karimi-Shahanjarini A, Zareian S, et al. Factors associated with preventive behaviours of COVID-19 among hospital staff in Iran in 2020: an application of the 
Protection Motivation Theory. J Hosp Infect [Internet]. 2020;105(3):430-3. Available from: https://www.sciencedirect.com/science/article/pii/S0195670120302103.

6. Bockarjova M, Steg L. Can Protection Motivation Theory predict pro-environmental behavior? Explaining the adoption of electric vehicles in the Netherlands. Glob Environ Chang [Internet]. 2014;28:276-88. Available from: https://www.sciencedirect.com/science/article/pii/S0959378014001150.

7. Hsu CHC, Huang S. Formation of tourist behavioral intention and actual behavior. In: 2010 7th International Conference on Service Systems and Service Management. 2010. p. 1-6.

8. Chamroonsawasdi K, Chottanapund S, Tunyasitthisundhorn P, Phokaewsuksa N, Ruksujarit T, Phasuksathaporn P. Development and Validation of a Questionnaire to Assess Knowledge, Threat and Coping Appraisal, and Intention to Practice Healthy Behaviors Related to Non-Communicable Diseases in the Thai Population. Behav Sci (Basel, Switzerland). 2017;7.

9. Cooper R. Water for the Urban Poor and COVID-19. In 2020.

10. Creswell JW, Creswell JD. Research design: Qualitative, quantitative, and mixed methods approaches. Thousand Oaks: SAGE Publications, Inc; 2018.

11. Demberere T, Muyambo M, Mutengu S, Ncozana T, Manyeruke N. An Analysis of the Effectiveness of Wash Interventions in Relation to Diarrhoeal Diseases in Chipinge District, Zimbabwe. Phys Chem Earth, Parts A/B/C. 2015 Jan 12;76-78.

12. Eppright DR, Tanner JF, Hunt JB. Knowledge and the ordered protection motivation model: Tools for preventing AIDS. J Bus Res [Internet]. 1994;30(1):13-24. Available from: https://www.sciencedirect.com/science/article/pii/0148296394900647.

13. Essendi H, Wandibba S. Barriers to health care by women infected withTuberculosis in Kibera slums in Nairobi, Kenya. African Popul Stud. 2011;25(1):17-33.

14. Ezbakhe F, Giné-Garriga R, Pérez-Foguet A. Leaving no one behind: Evaluating access to water, sanitation and hygiene for vulnerable and marginalized groups. Sci Total Environ [Internet]. 2019;683:537-46. Available from: https://www.sciencedirect.com/science/article/pii/S0048969719322466.

15. Fishbein M, Triandis H, Kanfer FH, Becker M, Middlestadt SE, Eichler A. Factors influencing behavior and behaviour change. Handb Heal Psychol Mahwah, NJ Lawrence Erlbaum. 2001 Jan 1;3-17.

16. Goodwin M, Perez E, Sivadol L, Kananant M, Pukij M, Suthumno PN, et al. Developing a Sustainable Drinking Water Management Model: Addressing Water Pollution In Khlong Toei Slum in Bangkok Thailand The Duang Prateep Foundation. 2015;(March). Available from: http://www.dpf.or.th/en/Magazine/KhlongWater_FinalReport.pdf.

17. Hair JF, HGT M, Ringle CM, Sarstedt M. A primer on partial least squares structural equation modeling. PLS-SEM); 2016.

18. He Z, Cheng Z, Shao T, Liu C, Shao P, Bishwajit G, et al. Factors Influencing Health Knowledge and Behaviors among the Elderly in Rural China. Int J Environ Res Public Health [Internet]. 2016 Sep 30;13(10):975. Available from: https://pubmed.ncbi.nlm.nih.gov/27706061. 
19. Hernández-Padilla JM, Granero-Molina J, Ruiz-Fernández MD, Dobarrio-Sanz I, López-Rodríguez MM, Fernández-Medina IM, et al. Design and Psychometric Analysis of the COVID-19 Prevention, Recognition and Home-Management Self-Efficacy Scale. Vol. 17, International Journal of Environmental Research and Public Health. 2020.

20. Hsan K, Naher S, Griffiths M, Shamol H, Rajman M. Factors associated with the practice of water, sanitation, and hygiene (WASH) among the Rohingya refugees in Bangladesh. J Water, Sanit Hyg Dev. 2019 Oct 21;9.

21. Islam S, Emran GI, Rahman E, Banik R, Sikder T, Smith L, et al. Knowledge, attitudes and practices associated with the COVID-19 among slum dwellers resided in Dhaka City: a Bangladeshi interviewbased survey. J Public Health (Bangkok) [Internet]. 2021 Mar 1;43(1):13-25. Available from: https://doi.org/10.1093/pubmed/fdaa182.

22. Janmaimool P. Application of Protection Motivation Theory to Investigate Sustainable Waste Management Behaviors. Vol. 9, Sustainability. 2017.

23. Johns Hopkins University. Coronavirus information [Internet]. Available from: https://covidinfo.jhu.edu/.

24. Kivimäki M, Singh-Manoux A, Pentti J, Sabia S, Nyberg ST, Alfredsson L, et al. Physical inactivity, cardiometabolic disease, and risk of dementia: an individual-participant meta-analysis. BMJ [Internet]. 2019 Apr 17;365:I1495. Available from:

http://www.bmj.com/content/365/bmj.I1495.abstract.

25. Konteh FH. Urban sanitation and health in the developing world: Reminiscing the nineteenth century industrial nations. Health Place [Internet]. 2009;15(1):69-78. Available from: https://www.sciencedirect.com/science/article/pii/S1353829208000191.

26. Leigh L, Taylor C, Glassman T, Thompson A, Sheu J-J. A Cross-Sectional Examination of the Factors Related to Emergency Nurses\&\#x2019; Motivation to Protect Themselves Against an Ebola Infection. J Emerg Nurs [Internet]. 2020 Nov 1;46(6):814-26. Available from: https://doi.org/10.1016/j.jen.2020.05.002

27. Milne S, Orbell S, Sheeran P. Combining motivational and volitional interventions to promote exercise participation: Protection motivation theory and implementation intentions. Br J Health Psychol. 2002 Jun;1:7:163-84.

28. Montoute MC, Cashman A. A knowledge, attitudes and practices study on water, sanitation and hygiene in Anse La Raye Village, Saint Lucia. CERMES Tech Rep; 2015.

29. Mortada E, Abdel-Azeem A, Al Showair A, Zalat MM. Preventive Behaviors Towards Covid-19 Pandemic Among Healthcare Providers in Saudi Arabia Using the Protection Motivation Theory. Risk Manag Healthc Policy [Internet]. 2021 Feb 17;14:685-94. Available from: https://pubmed.ncbi.nlm.nih.gov/33628067.

30. Mubarak MY, Wagner AL, Asami M, Carlson BF, Boulton ML. Hygienic practices and diarrheal illness among persons living in at-risk settings in Kabul, Afghanistan: a cross-sectional study. BMC Infect Dis [Internet]. 2016;16(1):459. Available from: https://doi.org/10.1186/s12879-016-1789-3. 
31. Nabizadeh SM, Taymoori P, Hazhir MS, Shirazi M, Roshani D, Shahmoradi B. Predicting vitamin E and $\mathrm{C}$ consumption intentions and behaviors among factory workers based on protection motivation theory. Environ Health Prev Med [Internet]. 2018;23(1):51. Available from: https://doi.org/10.1186/s12199-018-0742-z.

32. Nelson $\mathrm{K}$, Cismaru M, Cismaru R, Ono T. Water management information campaigns and protection motivation theory. Int Rev Public Nonprofit Mark [Internet]. 2011;8(2):163. Available from: https://doi.org/10.1007/s12208-011-0075-8.

33. Nguyen TPL, Seddaiu G, Virdis SGP, Tidore C, Pasqui M, Roggero PP. Perceiving to learn or learning to perceive? Understanding farmers' perceptions and adaptation to climate uncertainties. Agric Syst [Internet]. 2016;143:205-16. Available from: http://dx.doi.org/10.1016/j.agsy.2016.01.001.

34. Nguyen TP, Peña-García A Users' Awareness, Attitudes, and Perceptions of Health Risks Associated with Excessive Lighting in Night Markets: Policy Implications for Sustainable Development. Vol. 11, Sustainability. 2019.

35. Özdemir S, Elliott M, Brown J, Nam PK, Thi Hien V, Sobsey MD. Rainwater harvesting practices and attitudes in the Mekong Delta of Vietnam. J Water, Sanit Hyg Dev [Internet]. 2011 Sep 1;1(3):171-7. Available from: https://doi.org/10.2166/washdev.2011.024.

36. Park T, Ju I, Ohs J, Hinsley A. Optimistic bias and preventive behavioral engagement in the context of COVID-19. Res Soc Adm Pharm. 2020 Jun 1;17.

37. Pati S, KADAM SS, Chauhan A. Hand hygiene behavior among urban slum children and their care takers in Odisha, India. J Prev Med Hyg. 2014 Aug 5;55.

38. Pham V, Nguyen H, Tho L, Minh T, Lerdboon P, Riel R, et al. Evaluation of Three Adolescent Sexual Health Programs in Ha Noi and Khanh Hoa Province, Vietnam. AIDS Res Treat. 2012 May;17:2012:986978.

39. Podder D, Paul B, Dasgupta PA, Bandyopadhyay L, Pal A, Roy S. Community perception and risk reduction practices toward malaria and dengue: A mixed-method study in slums of Chetla, Kolkata. Indian J Public Health. 2019 Jul 1;63:178.

40. Pratkanis AR, Breckler SJ, Greenwald AG. Attitude structure and function. Hillsdale: Lawrence Erlbaum; 1989.

41. Renner B, Kwon S, Yang B-H, Paik K-C, Kim SH, Roh S, et al. Social-cognitive predictors of dietary behaviors in South Korean men and women. Int J Behav Med [Internet]. 2008;15(1):4-13.Available from: https://doi.org/10.1007/BF03003068.

42. Rippetoe PA, Rogers RW. Effects of components of protection-motivation theory on adaptive and maladaptive coping with a health threat. J Pers Soc Psychol [Internet]. 1987;52(3):596604.Available from: http://europepmc.org/abstract/MED/3572727.

43. Rogers RW. Cognitive and psychological processes in fear appeals and attitude change: A revised theory of protection motivation. New York: Soc Psychophysiol A Sourcebook,the Guilford Press; 1983. pp. 153-76. 
44. Stangier U, Kananian S, Schüller J. Perceived vulnerability to disease, knowledge about COVID-19, and changes in preventive behavior during lockdown in a German convenience sample. Curr Psychol. 2021; Tang J-S, Feng J-Y. (2018). Residents' Disaster Preparedness after the Meinong Taiwan Earthquake: A Test of Protection Motivation Theory. International Journal of Environmental Research and Public Health, 15(7). Available from: https://www.mdpi.com/1660-4601/15/7/1434.

45. UNICEF. WASH programme contribution to coronavirus disease (COVID-19) prevention and response [Internet]. 2021. Available from: https://www.unicef.org/documents/wash-programme-contributioncoronavirus-disease-covid-19-prevention-and-response. Accessed 3 March 2021.

46. UNESCO. Water, sanitation and handwashing in educational settings: Challenges and opportunities during covid19 context [Internet]. 2020. Available from: https://en.unesco.org/events/watersanitation-and-handwashing-educational-settings-challenges-and-opportunities-during. Accessed 3 March 2021.

47. Vivas AP, Gelaye B, Aboset N, Kumie A, Berhane Y, Williams M. Knowledge, Attitudes, and Practices (KAP) of Hygiene among School Children in Angolela, Ethiopia. J Prev Med Hyg. 2010 Jun;1:51:739.

48. World Bank. Water Supply, sanitation, and hygiene (WASH) poverty diagnostic initiative [Internet]. Available from: https://www.worldbank.org/en/topic/water/publication/wash-poverty-diagnostic. Accessed 3 March 2021.

49. Westcott R, Ronan $\mathrm{K}$, Bambrick $\mathrm{H}$, Taylor M. Expanding protection motivation theory: investigating an application to animal owners and emergency responders in bushfire emergencies. BMC Psychol [Internet]. 2017;5(1):13. Available from: https://doi.org/10.1186/s40359-017-0182-3.

50. Xiao H, Peng M, Yan H, Gao M, Li J, Yu B, et al. An instrument based on protection motivation theory to predict Chinese adolescents' intention to engage in protective behaviors against schistosomiasis. Glob Heal Res Policy [Internet]. 2016;1(1):15. Available from: https://doi.org/10.1186/s41256-0160015-6.

51. Zulu EM, Beguy D, Ezeh AC, Bocquier P, Madise NJ, Cleland J, et al. Overview of migration, poverty and health dynamics in Nairobi City's slum settlements. J Urban Heal [Internet]. 2011;88(2):185-99. Available from: https://doi.org/10.1007/s11524-011-9595-0.

\section{Appendix}

Appendix A is not available with this version.

\section{Figures}




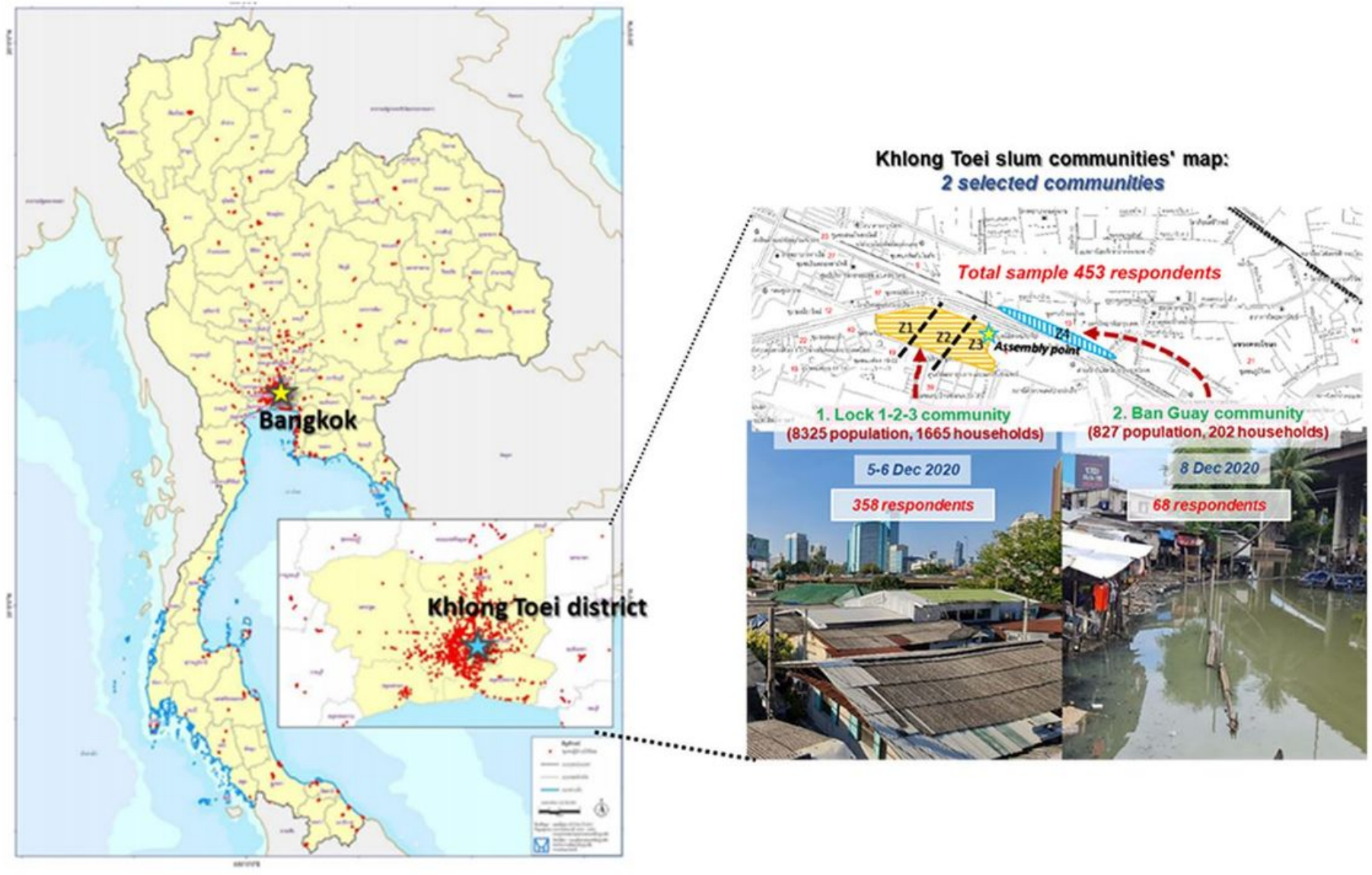

Figure 1

Lock 1-2-3 sub-communities and Ban Guay sub-communities, Khlong Toei slum communities in Khlong Toei district (Bangkok, Thailand) 


\section{Access to Clean water}

Non-access to tap water

- Rent water meter

"Around 100-200 household in our community just settled here so they do not have access tap water. They have to rent water from their friends or some houses are doing as business that people who rent water have to monthly pay with very high price rate community leader
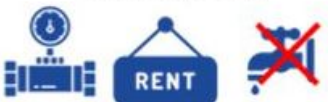

- Buying water from vending machine and use water from canal

"sometimes, I buy drinking water from vending machine and use water from canal and filter to clean water by myself' (Z2-migrant)

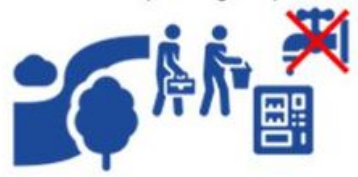

\section{Sanitation}

Poor sanitation

- Poor living environment without private toilet

"I live under toll way bridge. I do not have my own toilet. Sometimes, I just used the canal and used in my friend's house" (Z4-disabled)

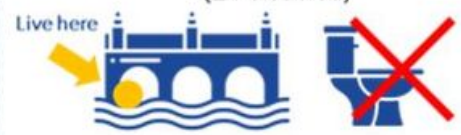

- No waste separation

"No, we do not separate waste. We just gather all garbage in plastic bags and put it in front of our house and then our community staff will come to collect at least once a week" (Z1-Adolescent)

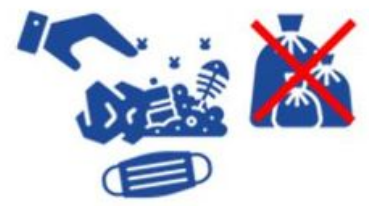

\section{Hygiene}

During lockdown: Good personal hygiene but some people's lack of WASH resources

- Wearing mask and washing hand

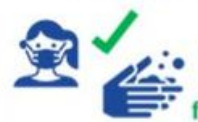

-...People listen and believe and do more. Know how to protect yourself wearing a mask, wash your hands frequently with clean water". (Z2-adult)

- Lack of disposable masks

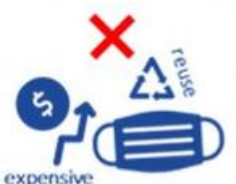

"All people change their behavior as they always wear face masks when they are in public places like shopping. They may not change their masks everyday but reuse it better than do nothing...". Community leader

Post lockdown: Careless of personal hygiene

- Less wearing mask

CE:- D

$\Rightarrow$ * $=2.54$
Since the government said that our country does not have COVID-19...but We still let foreigners. This is clear that our WASH is careless. Our measures are risky to spread again". Government officer

\section{Figure 2}

Interviewees' statements about their WASH conditions during the COVID-19 pandemic 


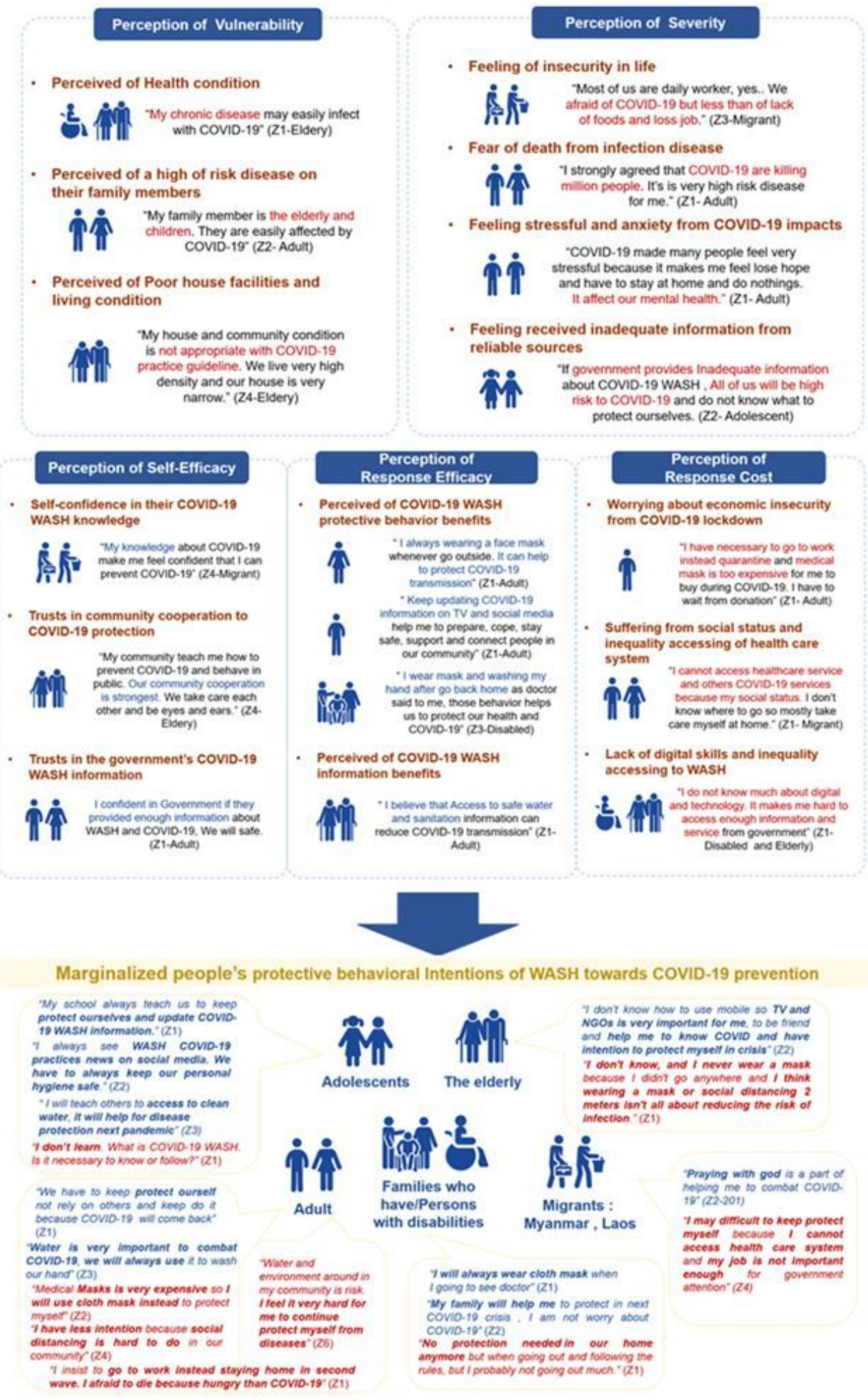

\section{Figure 3}

Marginalized people in slum communities' statements regarding COVID-19 prevention and, WASH facilities 


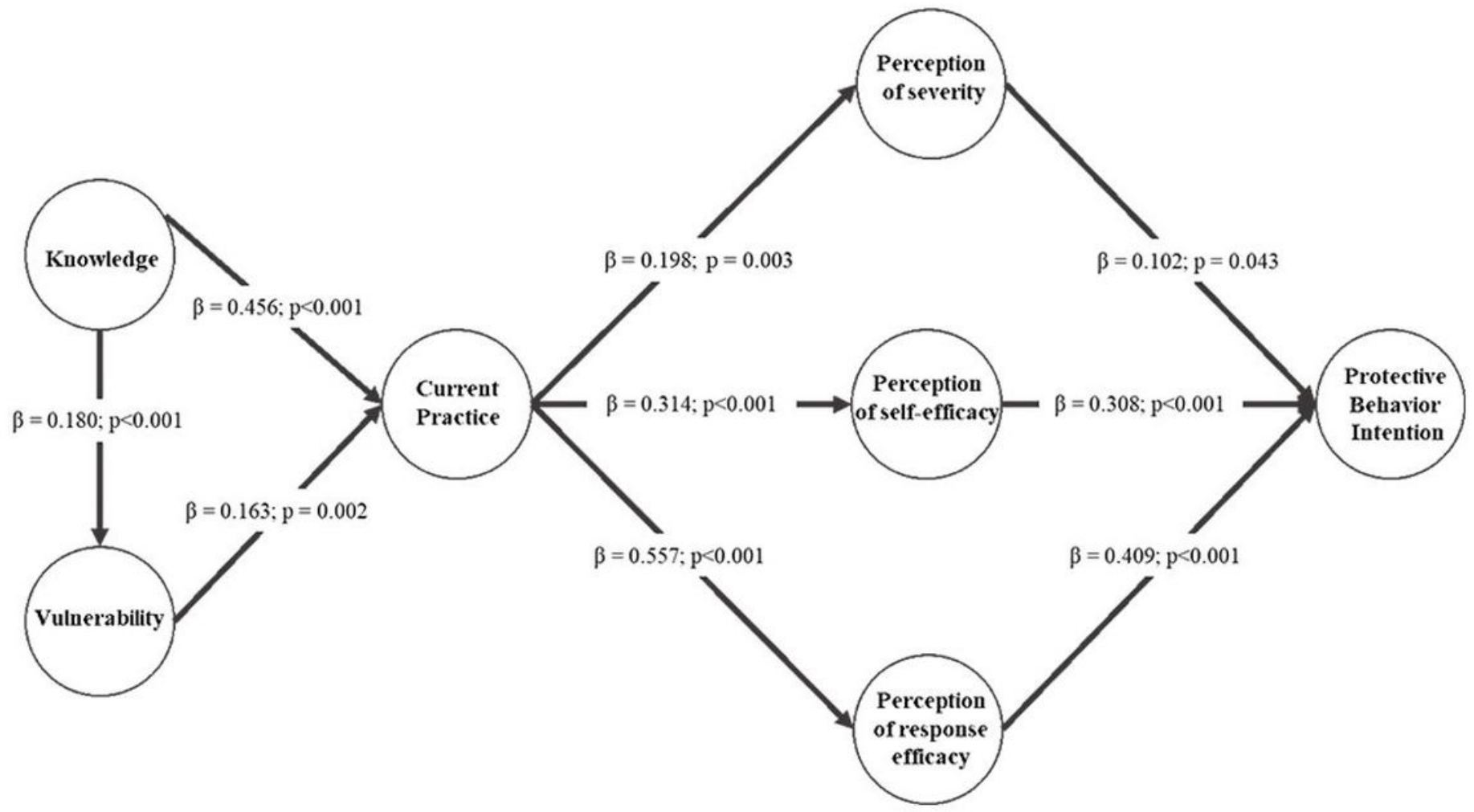

Figure 4

Structural equation modelling of Covid 19 related KAP- PMT constructs, and behaviours intention. 